\title{
Perancangan Aplikasi Gerbang Absensi Siswa Berbasis Web dan Arduino di SMK Negeri Kare (Studi Kasus Pada SMK Negeri Kare)
}

\author{
Bagas Pratama dan Slamet Riyanto \\ Teknik Informatika, Universitas PGRI Madiun \\ Email:bpratama369@gmail.com
}

\begin{abstract}
Abstrak. Penelitian ini melakukan kegiatan pengambilan data dengan melakukan observasi langsung ke SMK Negeri Kare dan melakukan wawancara kepada pegawai yang terkait dalam hal absensi yang bertujuan untuk mengamati system lama yang sudah berjalan.Hasil penelitian memberikan informasi bahwa merancang sebuah aplikasi absensi otomatis menggunakan RFID merupakan kebutuhan sekolah, dimana aplikasi tesebut dapat melakukan rekap absensi siswa secara otomatis. Dalam pembuatan aplikasi ini pemrograman dilakukan dengan menggunakan bahasa pemrograman HTML, PHP, Javascript dan farmwork node js. Dengan menggunakan aplikasi ini diharapkan nantinya akan mempermudah sistem absensi di sekolah.
\end{abstract}

Kata Kunci: Mikrokontroler, Sistem Absensi, Aplikasi Absensi.

Abstract. This study conducted data collection activities by directly observing Kare State Vocational School and conducting interviews with related employees in terms of attendance that aims to observe the old system that was already running. The research results provide information that designing an automatic attendance application using RFID is a school requirement, where the application can recap student attendance automatically. In making this application programming is done by using the programming languages HTML, PHP, Javascript and js node farmwork. By using this application it is hoped that later it will simplify the attendance system at school.

\section{Keywords: Microcontroller, Time Attendance System, Time Attendance Application}

\section{PENDAHULUAN}

Pada era teknologi informasi kini telah berpusat pada konsep serba otomatis. Semua dilakukan dengan bantuan mesin, secara tidak langsung manusia dituntut untuk lebih mengikuti dalam hal perkembangan teknologi. Dapat diambil contoh penerapan teknologi informasi pada sekolah untuk mempermudah dan mempercepat pekerjaan tenaga pendidik dan kependidikan.

Tugas dasar tim penertibialah perihal presensi siswa yang sering terjadi keteledoran. Karena menggunakan presensi manual yang sangat rawan manipulasi. Masih banyak siswa yang keluar masuk sekolah tanpa izin, bahkan meninggalkan sekolah tanpa sepengetahuan Guru Kelas ataupun penjaga sekolah karena tidak dilakukan penguncian gerbang sekolah oleh penjaga sekolah.Dapat diambil contoh pada SMK Negeri Kare yaitu tempat dilakukannya penelitian. Banyak sekali siswa yang meninggalkan sekolah tanpa sepengetahuan guru kelas sehingga banyak siswa yang pulang pada jam sekolah.

Dari kejadian ketidakdisiplinan presensi siswa di SMK tersebut, maka dibuatlah sistem yang membantu tenaga pendidik dan kependidikan SMK untuk mendisiplinkan siswa. Sistem yang dibuat yaitu SmkGate (Aplikasi Gerbang Absensi Siswa Berbasis Web dan Arduino Untuk Mempermudah Pengawasan Absensi Siswa). Sistem ini membantu siswa presensi secara otomatis. dalam penggunaannya sama dengan sistem 
gerbang otomatis yang membedakan yaitudapat merekam presensi siswa berdasarkan kedatangan siswa di sekolah. Sistem ini memadukan antara arduino dan web. Sistem ini hanya bekerja dua kali yaitu ketika siswa akan masuk dan ketika siswa akan keluar (pulang sekolah).

Pertanyaan penelitian yang akan dicapai adalah sebagai berikut : bagaimana hasil implementasi aplikasi gerbang absensi siswa berbasis web dan Arduino di SMK Negeri Kare?.

Batasan-batasan pada penelitian ini sebagai berikut :

1. Aplikasi ini hanya meliputi absensi dan gerbang otomatis.

2. Alat yang digunakan untuk scanner data absensi menggunakan RFID

3. Untuk rangkaian interface di sistem ini menggunakan Arduinouno

4. Pembuatan aplikasi pengolahan data menggunakan aplikasi berbasis web.

Tujuan penelitian yang akan dicapai adalah sebagai berikut : untuk menganalisis hasil implementasi aplikasi gerbang absensi siswa berbasis web dan Arduinodi SMK Negeri Kare.

\section{Landasan Teori}

Kusrini dan Andri (2007) menyatakan "Perancangan sistem adalah proses pengembangan spesifikasi sistem baru berdasarkan hasil rekomendasi analisis sistem. dalam tahap perancangan, tim kerja desain harus merancang spesifikasi yang dibutuhkan dalam berbagai kertas kerja. kertas itu harus memuat berbagai uraian mengenai input, proses, dan output dari sistem yang dibutuhkan"[1].

Riestiana dan Sukadi (2014) berpendapat bahwa perancangan sistem dibuat dan dibentuk supayaprogram yang dibuatmengikuti hasil dan aturan analisa yang telah dibuat pada perancangan program dengan cara memberi ketentuan proses dan bentuk pada perangkat lunak (software) yang dibuat [2].

\section{Wibawa dan Fany (2016)} berpendapat bahwa kegiatan untuk mengembangkan suatu proses dan procedure dalam keadaan sedang berjalan yang bertujuan membuat sistem baru ataupun memperbaharui sistem yang dulu sudah digunakan dan meningkatkan efektivitas kerja sistem yang sudah ada supaya hasil yang digunakan bisa terpenuhi dengan melakukan pemanfaatan fasilitas teknologi yang tersedia [3].

Kesimpulan dari pengertian perancangan sistem yang sudah diuraikan diatas perancangan sistem dapat diambil kesimpulan dengan batasan atau aturan saat membuat sistem supaya tidak menyimpang dari aturan yang sudah dianalisa sebelumnya.

Dharmawan (2017) menyatakan bahwa "Mikrokontroler merupakan chip mikrokomputer yang secara fisik berupa IC (Integrated Circuit). Mikrokontroler biasanya digunakan dalam sistem yang kecil, murah dan tidak membutuhkan perhitungan yang sangat kompleks seperti dalam aplikasi di PC" [4].

Sujarwata (2018) menyatakan "Mikrokontroler adalah sebuah sistem mikroprosessor lengkap yang terkandung didalam sebuah chip. Mikrokontroler berbeda dari mikroprosessor serba guna yang digunakan dalam sebuah personal computer(PC), karena sebuah mikrokontroler pada umumnya telah berisi komponen pendukung sistem minimal mikroprosesor, yakni memori dan antarmuka I/O" [5].

Artanto (2009) menyatakan "mikrokontroler adalah sebuah alat pengendali (kontroler) berukuran mikro atau sangat kecil yang dikemas dalam bentuk chip. Anda dapat menjumpai mikrokontroler dalam hampir semua alat elektronik yang kompleks. dari alat rumah tangga seperti mesin cuci hingga robotrobot mainan cerdas" [6].

$$
\text { Malik dan Juwana (2009) }
$$

menyatakan "Mikrokontroler adalah sebuah sistem komputer yang dibangun 
pada sebuah keping (chip) tunggal. Jadi, hanya dengan sebuah keping IC saja dapat dibuat sebuah sistem komputer yang dapat dipergunakan untuk mengontrol alat" [7].

Dari uraian diatas dapat disimpulkan bahwa mikrokontroler adalah

\section{Rancangan Penilitian}

Adapun flowchart rancangan penelitian yang dilakukan peneliti dalam menyelesaikan penelitian adalah sebagai berikut. sebuah alat yang bisa mengontrol rangkaian elektronik dengan ukuran mikro atau sangat kecil. Bisa disisipkan coding program untuk menjalankan perintah perintahnya.

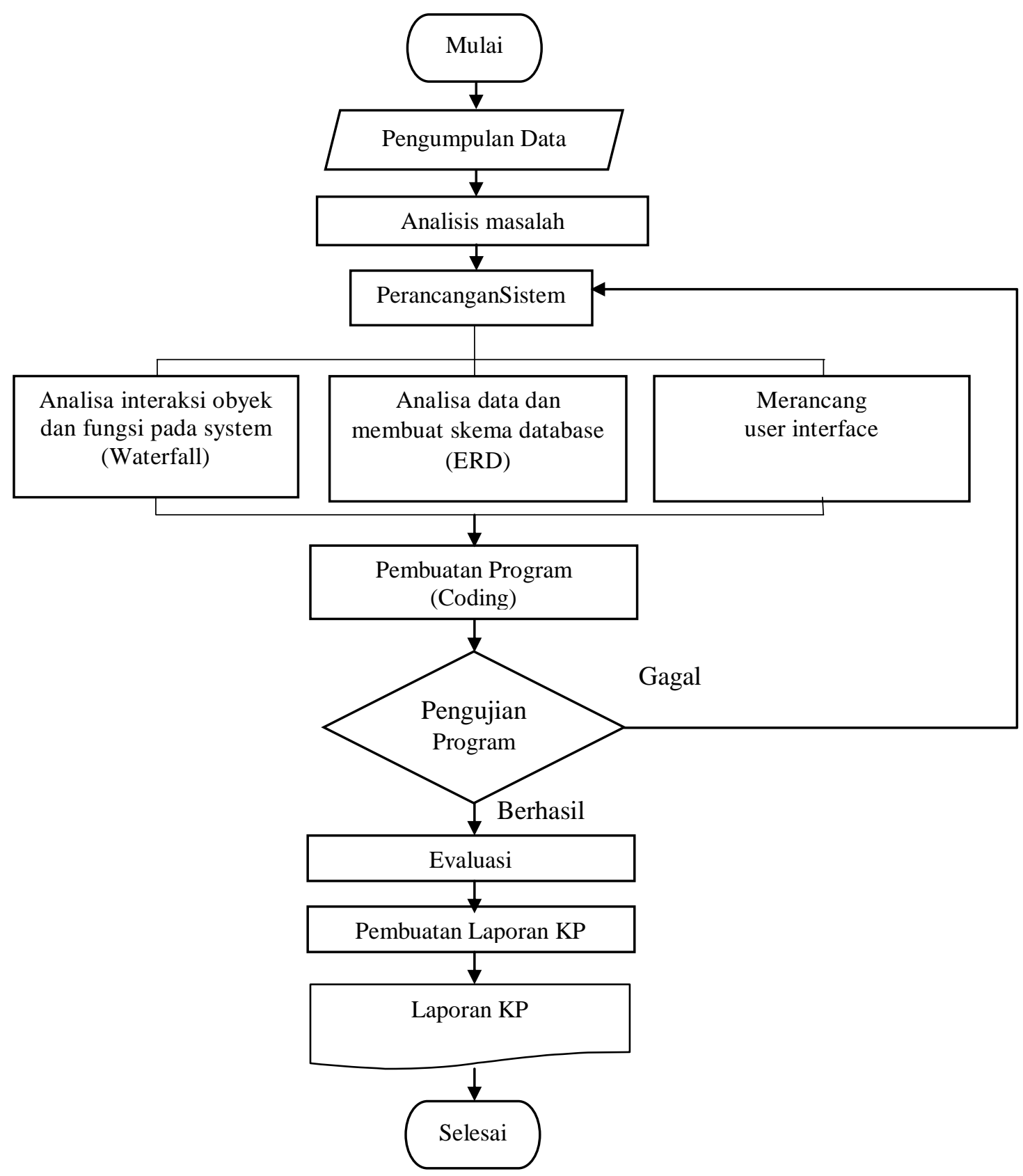

Gambar 1 Alur Rancangan Penelitian 


\section{Hasil Penelitian}

Implementasi adalah penerapan sistem gerbang absensi siswa berbasis web dan arduino yang telah dibuat di SMK Negeri Kare dengan tujuan sistem tersebut diharapkan sesuai dengan rancangan untuk dapat dioperasikan dan difungsikan dengan baik.sistem gerbang absensi siswa berbasis web dan arduino akan diinstall di komputer server sekolah sehingga dapat diakses lokal oleh tim penertib.

\section{Kegiatan Implementasi}

Kegiatan implementasi dilaksanakan sebagai berikut:

1. Pelatihan

Pelatihan dilakukan untuk menjelaskan kepada tim penertib tentang penggunaan sistem gerbang absensi siswa berbasis web dan arduino.

2. Spesifikasi Hardware dan Software

Sebelum dilakukan pemasangan sistem gerbang absensi siswa berbasis web dan arduino di komputer server sekolah maka diperlukan spesifikasi komputer yang sesuai dengan sistem yang telah dibuat. Berikut spesifikasi perangkat yang dibutuhkan:

a. Spesifikasi Perangkat Keras

(Hardware)

1) Ram : $1024 \mathrm{MB}$

2) Prosesor : Core i2 keatas

3) Hardisk : $500 \mathrm{~GB}$

4) Mikrokontroller : Arduino dan RFID

5) Printer: Printer Inkjet

b. Spesifikasi Perangkat Lunak (Software)

1) Sistem Operasi (Operating System) : Windows 7 keatas.

2) Visual Studio Code sebagai editor bahasa pemrograman.

3) MySQL sebagai database.

4) Node JS sebagai server tambahan.

\section{Implementasi Program}

1. Halaman indeks

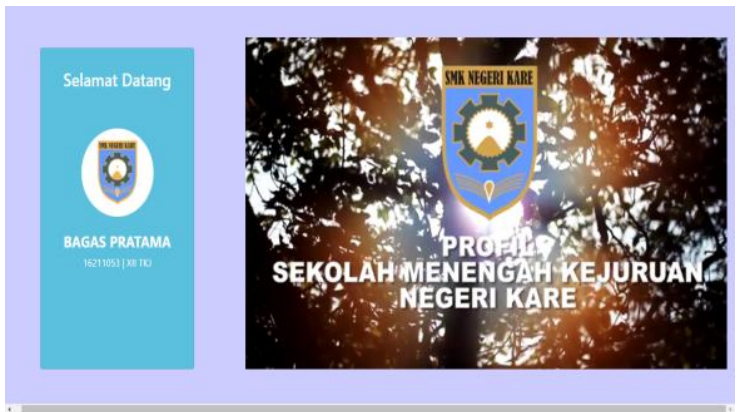

Gambar 2. Halaman Index

Halaman web yang ditampilkan di gerbang tanda siswa sudah absensi

2. Halaman Login

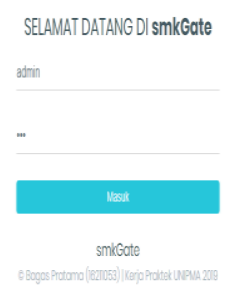

Gambar 3. Halaman Login

Login digunakan untuk memasukan username dan password untuk masuk ke menu utama

\section{Halaman Dhasboard}

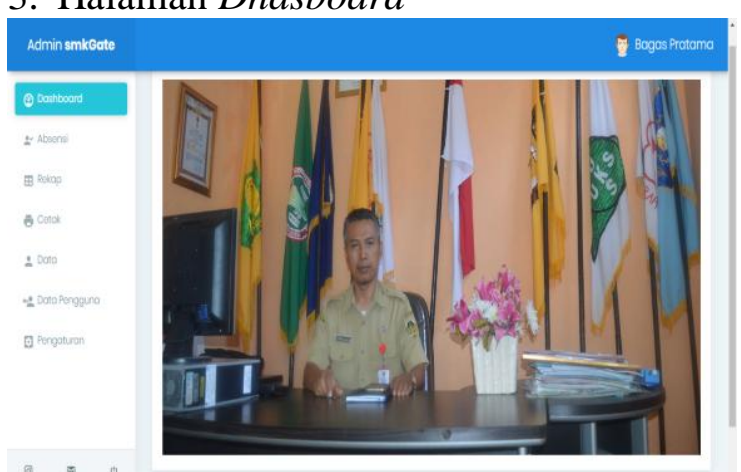

Gambar 4. Halaman Dhasboard

Halaman Dhasboard merupakan halaman utama setelah melakukan login yang terdapat berbagai menu absensi, rekap, cetak, data, data pengguna, pengaturan. 


\section{Halaman Absensi}

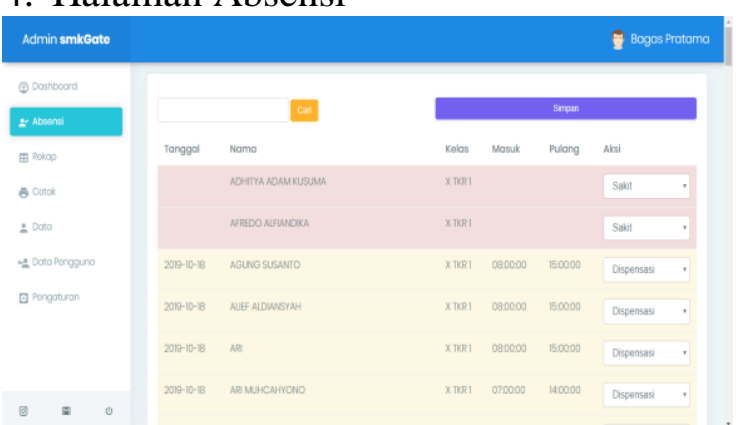

Gambar 5 Halaman Absensi

Halaman absensi merupan halaman untuk mengecek siswa yang tidak masuk dengan memberi keterangan alasan siswa yang tidak masuk tersebut.

\section{Halaman Rekap}

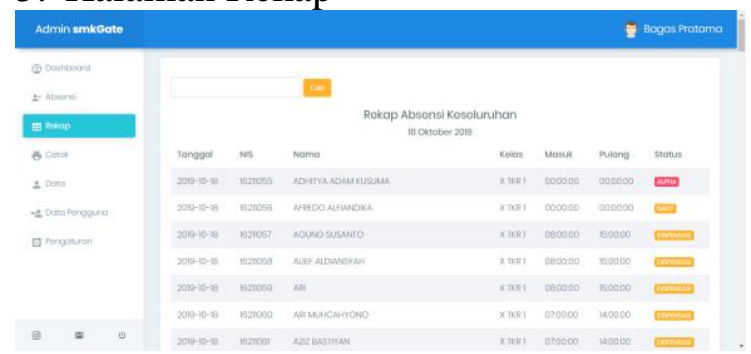

Gambar 6. Halaman Rekap

Halaman ini menampilkan status keseluruhan siswa di hari tersebut

6. Halaman Cetak

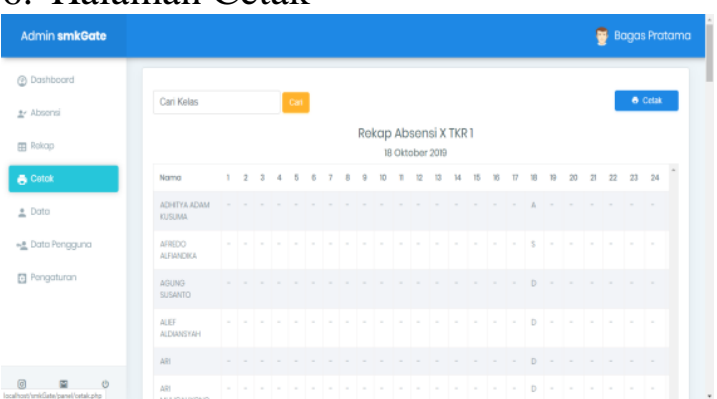

Gambar 7. HalamanCetak

Halaman ini menampilkan laporan bulanan absensi perkelas sebelum dicetak.

7. Halaman cetak saat di print

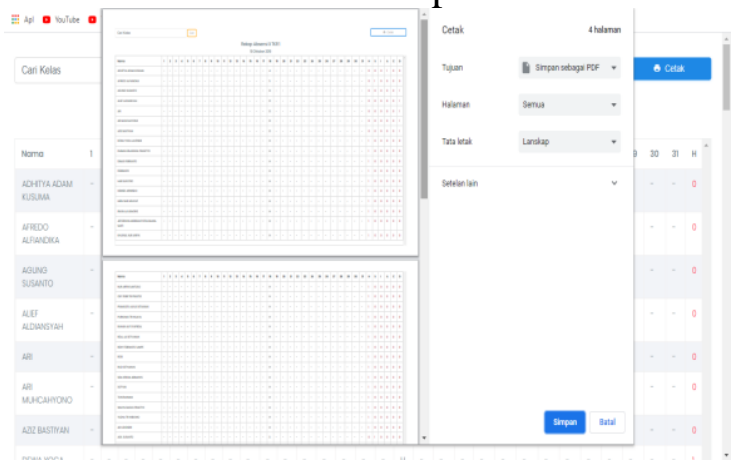

Gambar 8. Halaman cetak saat di print Halaman ini menampilkan laporan bulanan absensi perkelas saat dicetak.

8. Halaman Data

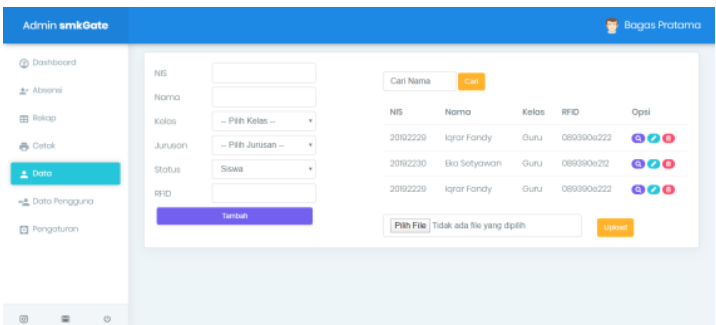

Gambar 9. Halaman Data

Menu halaman data digunakan untuk melakukan tambah, ubah, hapus dan melihat detail siswa dan guru.

9. Halaman Data Pengguna

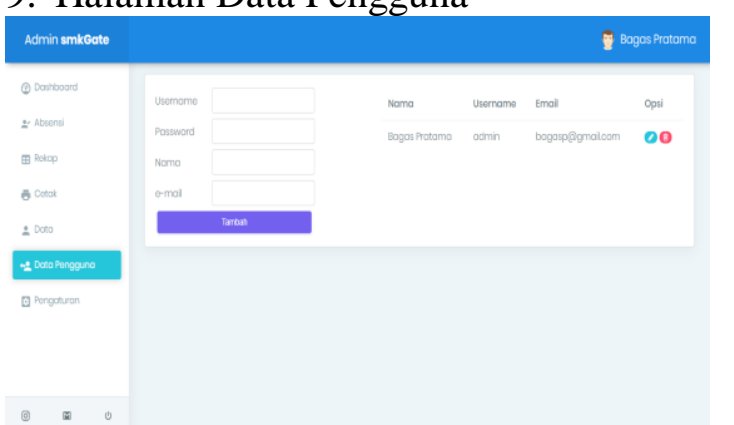

Gambar 10. Halaman Data Pengguna

Menu halaman data pengguna digunakan untuk melakukan tambah, ubah dan hapus data pengguna.

10. Halaman Pengaturan

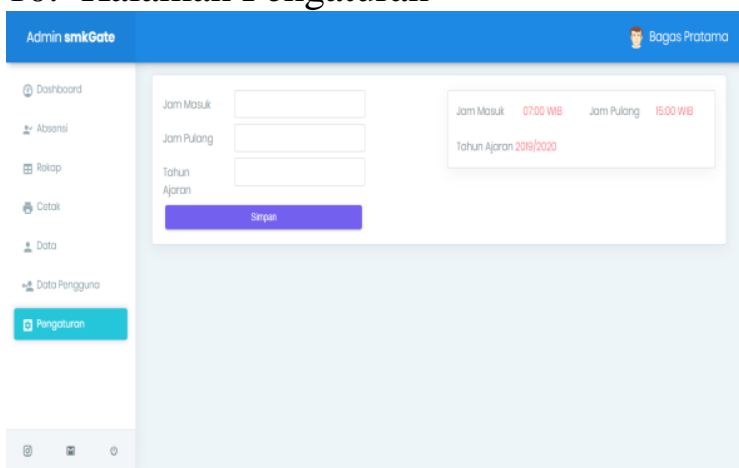

Gambar 11. Halaman Pengaturan

Menu pengaturan berfungsi untuk merubah jam masuk, jam pulang dan tahun ajaran.

\section{Evaluasi}

Setalah melakukan evaluasi dengan melakukan observasi di SMK Negeri Kare maka dapat di ambil poin bahwa sistem ini memiliki kekurangan 
yang menyebabkan keterbatasan penggunaanya, maka hasil dari evaluasinya adalah:

1. Sistem ini masih menggunakan Local Area Networking dimana hanya dapat diakses secara internal oleh pihak sekolah. Sehingga pengembangan yang dapat dilakukan dalam hal ini dengan membuat supaya sistem ini bisa diakses onlinesehingga kepala sekolah bisa melakukan cek walau tidak berada sisekolah.

2. Sistem ini menggunakan RFID dimana kelemahan dari RFID sendiri adalah siswa dapat menitipkan absensi ke temannya. Sehingga pengembangan dari masalah ini bisa ditambahkannya CCTV untuk memantau siswa yang melakukan absensi apakah melakukan absensi secara ganda atau tidak.

3. Sistem ini masih belum bisa mengirim pemberitahuan kepada wali murid tentang kehadiran siswa ke sekolah sehingga wali murid tidak mengetahui apakah anaknya masuk sekolah atau tida. Sehingga penggembang dari masalah ini bisa dilakukannya penambahan fitur sms gateway untuk menggirim pemberitahuan kepada wali murid.

4. Sistem ini tidak akan bisa membuka gerbang apabila kartu RFID tidak terbawa sehingga tim yang bertugas akan membukakan dengan kartu miliknya. Sehingga pengembangan dari masalah ini bisa dilakuakn penambahan Finger Print untuk melakukan pembukaan pintu gerbang ketika tidak membawa kartu RFID.

5. Sistem ini masih terbatas fungsinya dengan tidak bisa melakukan rekap poin jika siswa melakukan tidak ikut pelajaran. Sehingga pengembangan yang bisa dilakukan adalah dengan menambah fitur rekap poin siswa yang terhubung dengan aplikasi poin di SMK Negeri Kare.

6. Sistem ini masih menggunakan palang pintu dari gafaum sehingga masih bisa dilompati siswa keluar masuk sekolah tetapi kendaraan masih berada didalam sekolah. Sehingga pengembangan yang bisa dilakukan adalah dengan mengganti palang dengan gerbang geser otomatis.

\section{Kesimpulan}

Dari hasil penelitian dan analisis yang telah penulis lakukan maka dapat disimpulkan bahwa:

1. Dengan melakukan pengumpulan data menggunakan metode wawancara dan observasi maka memperoleh rancangan sistem yang akan dibuat. Dengan itu Penerapan rancangan dari sistem aplikasi gerbang absensi siswa berbasis web dan arduimo bisa dilaksanakan.

2. Setelah dilakukan penerapan sistem gerbang absensi siswa berbasis web dan arduino dapat mempermudah pekerjaan tim penertib saat melakukan absensi siswa dengan adanya sistem tersebut tim penertib sudah tidak melakukan rekap absensi secara manual saat pagi hari dilakukan apel.

3. Setelah dievaluasi setelah sistem gerbang absensi siswa berbasis web dan arduino diterapkan masih memiliki kekurangan mulai dari keterbatasan jangkauan untuk mengaksesnya masih menggunakan local area networking.

\section{Saran}

Dari beberapa kesimpulan yang telah diambil, maka dapat dikemukakan saran-saran yang akan sangat membantu dalam pengembangan perangkat lunak ini selanjutnya. Adapun saran-saran yang akan disampaikan antara lain : Bagi SMK Negeri Kare, yaitu perlu dikembangkan sistem ini agar bisa diakses secara online, menambahkan jumlah gerbang yang digunakan dan menggunakan rasbery pi untuk menjalankan program supaya tidak ribet di box. Bagi peneliti lain, perlu menambahkan fitur sms gateway untuk memberi tahu kehadiran siswa ke wali murid dan mengembangkan kartu rfid agar bisa digunakan untuk alat menabung. 


\section{Daftar Pustaka}

[1] Kusrini dan Andri, K. (2007). Tuntunan Praktis Membangun Sistem Informasi Akuntansi Dengan Visual Basic dan Microsoft SQL Server. Yogyakarta: CV Andi Offset

[2] Riestiana, M dan Sukadi. (2014). Sistem Informasi Penggajian Karyawan Pada Commenditaire Vennontschap (CV) RGL Bordir Dan Konveksi Pacitan. Journal Speed Sentra Penelitian Engineering dan Edukasi, 6, (4), 31-37.

[3] Wibawa, J, C dan Fany, J. (2016). Rancang Bangun Sistem Informasi Kepegawaian (Studi Kasus : PT Dekatama Centra). Jurnal Teknik Informatika dan Sistem Informasi, 2, (2), 173-185
[4] Dharmawan, H, A. (2017). Mikrokontroler Konsep Dasar dan Praktis. Malang:UBMedia

[5] Sujarwata. (2012). Belajar Mikrokontroler BS2SX Teori Penerapan dan Contoh Pemrograman Pbasic. Sleman: CV Budi Utama

[6] Artanto, D. (2009). Merakit PLC Dengan Mikrokontroler. Jakarta:Gramedia

[7] Malik, M, I dan Juwana, M, U. (2009). Aneka Proyek Mikrokontroler PICI6F84A. Jakarta: PT Gramedia 